\title{
The effect of cannabis exposure on pubertal outcomes: a systematic review
}

REVIEW

\author{
E Danielle Sims ${ }^{1-3}$ \\ Sama Anvari ${ }^{1,2,4, *}$ \\ Yung Lee L,2,4,* $^{1,2,4}$ \\ Zainab Samaan ${ }^{5}$ \\ Laura Banfield ${ }^{6}$ \\ Lehana Thabane ${ }^{1,7-10}$ \\ M Constantine Samaan ${ }^{1-4,7}$ \\ 'Department of Pediatrics, McMaster \\ University, Hamilton, ON, Canada; \\ ${ }^{2}$ Division of Pediatric Endocrinology, \\ McMaster Children's Hospital, \\ Hamilton, ON, Canada; ${ }^{3}$ Medical \\ Sciences Graduate Program, McMaster \\ University, Hamilton, ON, Canada; \\ ${ }^{4}$ Michael G. De Groote School of \\ Medicine, McMaster University, \\ Hamilton, ON, Canada; ${ }^{5}$ Department \\ of Psychiatry and Neurobehavioral \\ Sciences, McMaster University, \\ Hamilton, ON, Canada; ${ }^{6} \mathrm{Health}$ \\ Sciences Library, McMaster University, \\ Hamilton, ON, Canada; ${ }^{7}$ Department \\ of Health Research Methods, Evidence \\ and Impact, McMaster University, \\ Hamilton, ON, Canada; ${ }^{8}$ Department \\ of Anesthesia, McMaster University, \\ Hamilton, ON, Canada; ${ }^{9}$ Centre for \\ Evaluation of Medicines, Hamilton, \\ ON, Canada; ${ }^{10}$ Biostatistics Unit, St. \\ Joseph's Healthcare, Hamilton, ON, \\ Canada \\ *These authors contributed equally to \\ this work
}

Correspondence: M Constantine Samaan Department of Pediatrics, McMaster University, 1280 Main Street West, HSC-3A57, Hamilton, ON L8S 4KI, Canada

Tel + I 90552 I 2100ext75926

Fax +l 9053087548

Email samaanc@mcmaster.ca
This article was published in the following Dove Press journal:

Adolescent Health, Medicine and Therapeutics

Purpose: Several countries are legalizing the use of medicinal cannabis and easing restrictions on its recreational use. While adults have been the primary target of these initiatives, expanding access to cannabis will likely lead to increased use by children. While the effects of cannabis on pediatric neuropsychological and mental health outcomes have been broadly studied, there are limited data on the physical health effects of cannabis, including endocrine health. Animal studies have shown that chronic cannabis use leads to delayed sexual maturation; however, its effects on pubertal outcomes in children are not well studied. This systematic review aimed to assess the effect of cannabis use on pubertal timing and tempo in children.

Methods: We conducted a systematic review with literature searches in MEDLINE, Embase, Cochrane Database of Systematic Reviews, Central, PsycINFO, CINAHL, Web of Science, and SPORTDiscus from inception to February 2018. A gray literature search was also completed in Clinicaltrials.gov and ProQuest Dissertations and Theses A\&I. The primary outcome was pubertal timing, while secondary outcomes included pubertal tempo and final height and weight. We had no restrictions on date or language of publication of papers. Two reviewers independently assessed records for eligibility, with a third reviewer resolving disagreements.

Results: Our database and gray literature searches identified 759 records. A total of 29 full-text papers were assessed for eligibility. However, all studies were ultimately excluded as they did not meet the eligibility criteria.

Conclusion: Our results highlight a significant gap in existing literature regarding the effects of cannabis use on puberty. Adequately powered longitudinal studies are urgently needed to provide pediatricians and other health care providers with high-quality information on the potential effects of cannabis on the physical health of children.

Prospective Registrar of Systematic Reviews Registration: PROSPERO no.: CRD42018089397.

Keywords: marijuana, puberty, children, pediatric, tetrahydrocannabinol, cannabis

\section{Introduction}

Several countries and jurisdictions have decriminalized or legalized the use of medicinal and recreational cannabis, and many others are considering this policy change. ${ }^{1-6}$ While cannabis is not legalized for use by children ( $<18$ years), this has not limited the access of this group. In a large national survey, $15.5 \%$ of US youth report using cannabis by Grade 8 and this rises to $44.7 \%$ by Grade 12 ; the daily use of cannabis in Grade 8 students has increased from $0.2 \%$ in 1991 to $1.1 \%$ in $2015 .{ }^{7,8}$ With legalization, children will likely have increased access to cannabis and there is a need to understand the effects of its use on health. ${ }^{7,9}$ 
While studies have focused on the mental and neurocognitive effects of cannabis use, ${ }^{10-13}$ there is currently limited evidence regarding the effects of its use on the physical health of children, including endocrine and metabolic health.

Importantly, children undergo a pubertal transition that represents a critical period of physical, emotional, and mental development. A key component of this transition is the production of sex steroids, and perturbation of puberty can have lifelong implications on growth, metabolism, and accrual of bone mass. ${ }^{14-24}$ Therefore, understanding the implications of cannabis use on physical health in children is critical.

There is evidence from animal studies that cannabis use can lead to pubertal delay, with some evidence suggesting windows of effect on pubertal maturation. ${ }^{25-27}$ Specifically, exposure to $\Delta$-9-tetrahydrocannabinol $(\Delta-9$-THC), the primary active compound in cannabis, is associated with delayed sexual maturation and growth spurt in rats. ${ }^{28}$

While evidence is limited in humans, a case report noted delayed puberty and low testosterone levels with heavy cannabis smoking. ${ }^{29}$ When the 16 -year-old youth discontinued cannabis, his testosterone levels increased, with advancement in growth velocity and pubertal development. ${ }^{29}$ Furthermore, lower testosterone levels have been reported in adult males with chronic use of cannabis compared to age-matched controls who did not use cannabis. ${ }^{30}$ While some of the actions of sex steroids are different in adults compared to children, they are needed in children to go through puberty, which can impact growth, attainment of secondary sexual characteristics, sexual function, bone mass accrual, and psychological well-being.

There is an urgent need to understand the health effects of cannabis use on pubertal timing and tempo in children. This systematic review aims to report on the effects of cannabis use on puberty in humans.

\section{Materials and methods}

This systematic review is registered with the International Prospective Register of Systematic Reviews (PROSPERO no. CRD42018089397) and is reported according to the Preferred Reporting Items for Systematic Reviews and Meta-Analyses (PRISMA) statement (Table S1).

\section{Literature searches}

A Senior Health Sciences Librarian designed the search strategy. Database searches were completed in MEDLINE, Cochrane Central Register of Clinical Trials, Cochrane Database of Systematic Reviews, PsycINFO, Embase, Web of Science, SPORTDiscus, and CINAHL. A gray literature search was also conducted in ProQuest Dissertations and Theses A\&I and Clinicaltrials.gov. There were no restrictions on the timing of study conduct or language of study. Literature searches are up to date to February 2018. A sample of the MEDLINE search strategy is reported in Table 1. Other search strategies are included in Tables S2-S9.

\section{Inclusion and exclusion criteria}

Studies including boys and girls who are less than 18 years of age with exposure to recreational or medicinal cannabis were included in this review. The use of cannabis included smoked, ingested, and all other modes of exposure to cannabis products as reported. A minimum of 10 study participants were required for the study to be considered eligible for inclusion.

Eligible study designs included randomized controlled trials, observational studies, prospective and retrospective cohort studies, and case-control studies. Case reports, reviews, and preclinical or animal studies were excluded.

\section{Study selection}

Title, abstract, and full-text screening was independently assessed against the eligibility criteria at each stage by two reviewers. A third reviewer was consulted to resolve persistent disagreements. Reference lists of relevant review articles were hand-searched to identify any additional articles eligible for inclusion in this review.

Table I MEDLINE search strategy

\begin{tabular}{|c|c|}
\hline$\#$ & Searches \\
\hline I & Cannabis/ \\
\hline 2 & exp Cannabinoids/ \\
\hline 3 & marijuana.mp. \\
\hline 4 & cannabi*.mp. \\
\hline 5 & marihuana.mp. \\
\hline 6 & ganja*.mp. \\
\hline 7 & bhang*.mp. \\
\hline 8 & or/l-7 \\
\hline 9 & exp Pubertyl \\
\hline 10 & pubert*.mp. \\
\hline II & sex* precoci*.mp. \\
\hline 12 & puberty, delayed/or puberty, precocious/ \\
\hline 13 & Sexual Development/ \\
\hline 14 & Sexual Maturation/ \\
\hline 15 & (sexual adj2 (development or matur*)).mp. \\
\hline 16 & or/9-15 \\
\hline 17 & 8 and 16 \\
\hline 18 & remove duplicates from 17 \\
\hline 19 & I 8 not (animals/not (humans/and animals/)) \\
\hline
\end{tabular}




\section{Data abstraction}

A data abstraction form was developed specifically for this systematic review. Our primary outcome of interest was pubertal timing reported in years or months. The secondary outcomes included pubertal tempo and final height and weight. Tanner staging was the chosen method to assess puberty. ${ }^{31,32}$ We planned to collect data including the first author's name, year of publication, study design, country, setting, population, sample size, and sex distribution.

Data on cannabis exposure were also to be recorded noting the duration of use, route of administration, dose, frequency, and potential confounders including the use of other illicit drugs, alcohol intake and tobacco smoking. In the case of studies including a control group, data assessing the primary and secondary outcomes were to be abstracted for both groups. For studies including combined data for pediatric and adult populations or if the data included the use of other drugs, the Principal Investigator would be contacted to request data for the pediatric population specifically for cannabis.

\section{Risk of bias and quality assessment}

Two reviewers planned to independently assess the risk of bias as well as overall quality of the evidence. We chose the Cochrane risk of bias tool for randomized controlled trials ${ }^{33}$ and Newcastle-Ottawa scale (NOS) to determine the quality of observational studies. ${ }^{34}$

If multiple studies had similar study designs, populations, and reported outcomes, the Grading of Recommendations, Assessment, Development, and Evaluation (GRADE) guidelines were chosen to determine the overall quality of evidence. $^{35}$

\section{Statistical analysis}

A meta-analysis would be conducted if two or more studies had similar design, methods, populations, and outcomes. Dichotomous and continuous outcomes were to be reported as ORs and standardized mean differences with $95 \% \mathrm{CIs}$, respectively. If possible, a subgroup analysis based on sex will be performed if sufficient data are available.

To evaluate heterogeneity among studies, the inconsistency index $\left(I^{2}\right)$ would be used. The Cochrane Collaboration guidelines would be used to determine the level of heterogeneity across studies. ${ }^{36} \mathrm{An} I^{2}>75 \%$ and a $P$-value of $<0.05$ would represent considerable heterogeneity among studies. ${ }^{36}$ If ten or more studies reported the same outcome, Egger's test to determine the publication bias in addition to interpreting a contour-enhanced funnel plot was chosen. ${ }^{37}$

\section{Results}

The screening process is reported in Figure 1. The database searches retrieved 706 records, and 53 records were identified through gray literature search. Of the 759 records retrieved, 181 duplicates were removed, leaving 578 unique records for title screening, and from these 96 records were eligible for abstract screening. Abstract screening identified 29 eligible records for full-text screening. All articles $(n=29)$ were excluded following full-text screening as they did not meet the eligibility criteria.

There was one abstract that reported that plasma concentrations of the luteinizing hormone ( $\mathrm{LH})$, testosterone, and cortisol were significantly higher in boys using cannabis $(\mathrm{n}=217)$, but plasma growth hormone $(\mathrm{GH})$ concentrations were lower during puberty in the cannabis group $(\mathrm{n}=220){ }^{38}$ Furthermore, the control group was taller and weighed more at the age of 20 years compared to cannabis users. ${ }^{38}$ However, no full-text publication was identified from this work, and with the limited methodological details available and the number of confounders, it was ultimately excluded.$^{38} \mathrm{We}$ attempted to contact the Principal Investigator of the study, however, were unable to obtain additional data.

Due to the limited evidence base, we searched records for any eligible records with less than ten subjects, including case studies or reports. However, only the one case report was identified. ${ }^{29}$

\section{Discussion}

As the use of cannabis rises, ${ }^{7,8}$ the effects of its use on children's health are still widely unknown. Based on animal data and very limited evidence from human studies, the exposure of children to cannabis may affect pubertal development and growth spurt. In addition, pubertal hormones are important contributors to bone mass accrual and the effect of cannabis use on bone health is important to understand. ${ }^{15}$ This systematic review evaluated the existing evidence on the effect of cannabis exposure on pubertal outcomes in children. Following a comprehensive literature search and screening process, no existing articles provided answers to the question of cannabis effects on puberty.

Cannabis consists of several compounds called cannabinoids, and $\Delta-9$-THC is its main psychoactive component. ${ }^{39}$ With limited clinical data, animal studies are one of the few models that may provide insights on the potential impact of cannabis use on pediatric endocrine and metabolic health. ${ }^{40}$ The administration of $\Delta-9$-THC to animals leads to delayed sexual maturation and impaired gonadal function. ${ }^{26}$ For example, female rats receiving $\Delta-9-\mathrm{THC}$ had fewer ova 


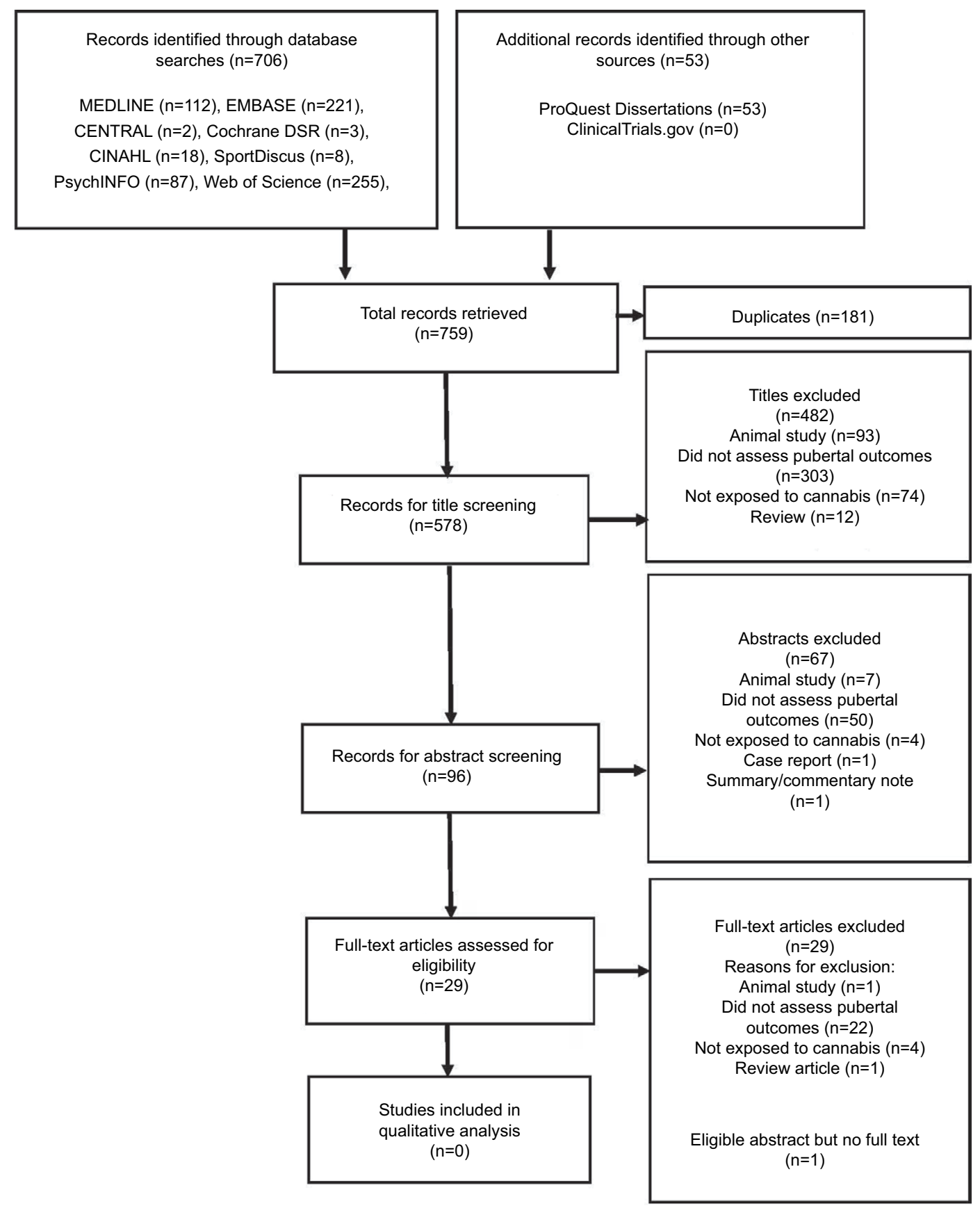

Figure I Flow diagram of screening process.

on the first day of estrus when compared with controls..$^{25,41}$ Furthermore, the female rats receiving $\Delta-9$-THC had lower levels of LH during proestrus, estrus, and diestrus and lower follicle-stimulating hormone (FSH) at diestrus. ${ }^{25}$ In male rats, chronic administration of $\Delta-9$-THC led to significant reduction in the pubertal growth spurt when compared with controls with lower endogenous testosterone, dihydrotestosterone (DHT), LH, and FSH levels in $\Delta$-9-THC-treated rats, which likely explain the noted phenotype. ${ }^{28} \mathrm{As} \mathrm{LH}$ and FSH stimulate gonadal production of testosterone and estradiol, gametogenesis, and ovulation, animal data suggest that cannabis affects the hypothalamic-pituitary-gonadal axis..$^{42-44}$

The preclinical reports on important effects of chronic exposure to $\Delta-9$-THC on puberty may be relevant to inform human studies. Importantly, the daily doses administered to rodents in these studies varied from $4 \mathrm{mg} / \mathrm{kg}^{28}$ to as low as $0.001 \mathrm{mg} / \mathrm{k}^{25,41}$ which are comparable to the doses of $\Delta-9$ THC exposure in humans that range from 0.1 to $3.9 \mathrm{mg} / \mathrm{kg} .{ }^{45}$ 
With the progressive increase in daily use of cannabis in children, ${ }^{7}$ the physical health effects of exposure, as well as dosing and frequency on pubertal development, are increasingly important to understand and need to be considered in future studies.

While there were no eligible studies for inclusion in this systematic review, we identified one case report and one abstract relevant to our topic. ${ }^{29,38}$ Both records supported the observations from preclinical studies that cannabis use may impact pubertal development. The two reports included only male subjects and both observed delayed puberty and reduced growth spurt in cannabis users. ${ }^{29,38}$ However, while the case report observed lower testosterone levels with cannabis use, ${ }^{29}$ the abstract we identified reported higher concentrations of $\mathrm{LH}$, testosterone, and cortisol, yet lower $\mathrm{GH}$ concentrations in cannabis users compared to controls. ${ }^{38}$ This abstract suggested that cannabis use may accelerate puberty and suppress growth. There were several descriptors that were not reported in the abstract, and this precluded the confirmation of the conclusion of the abstract. This limited evidence base needs to be interpreted with caution and does not fully clarify the potential impact of cannabis on puberty.

In the general population, delayed pubertal development has been associated with future adverse health outcomes in adults. Studies in non-cannabis users have found that delayed puberty in men may lead to reduced bone mineral density compared to those with normal puberty. ${ }^{15}$ In women, delayed menarche is a potential risk factor for low peak bone mass as well as irregular menstrual cycles and infertility. ${ }^{46,47}$ Therefore, understanding the effect of cannabis exposure on pubertal development in children is important to monitor those who may be at risk of future health concerns.

There is also some evidence linking infertility with cannabis use. Studies in adults have suggested that women were twice as likely to experience infertility if they had smoked cannabis within a year of attempted conception, compared to women who had never used cannabis..$^{48,49}$

Male rat studies demonstrated a significant decrease in the progressive motility of sperms, sperm counts, and seminiferous tubules' development with cannabis use compared with controls. ${ }^{50} \mathrm{~A}$ study on human sperms found that cannabis exposure resulted in a sperm quality and concentration. ${ }^{51}$

Adequately powered prospective cohort studies are needed to address the impact of cannabis use in children and adolescents on pubertal timing, tempo, final height, sexual maturation, sexual function, and future fertility.

The main strengths of this systematic review include the pursuit of an extensive search strategy and its rigorous methodology. There were no restrictions in terms of language or date of publication of papers.

The main limitation of this review is the lack of studies evaluating the use of cannabis in humans and its effect on pubertal outcomes.

\section{Conclusion}

There is an important gap in the existing evidence base linking cannabis and pubertal outcomes in children. Preclinical studies have suggested potential negative effects of cannabis use on sexual maturation, gonadotrophins, and gonadal function. However, there are currently no existing longitudinal studies to evaluate these and other physical health effects in children. Despite the increased cannabis use in children and adolescents, ${ }^{7}$ the main focus of research has been on the psychiatric outcomes and neurocognitive deficits resulting from its use, while the impact on physical health has received less attention. ${ }^{10}$ Pediatricians and other health care providers require high-quality information to council their young patients regarding the potential physical health effects of cannabis, as this may influence the decision of children and youth to use cannabis. In addition, this information may also clarify the need for policy makers to support the development of screening and treatment strategies for those who decide to use cannabis, if potential negative health impacts are identified to reduce potential harms on physical health and development.

As puberty is a critical window of physical growth and development, the fact that there are no studies addressing cannabis effects on these aspects of health makes this a critical area of future investigation in this new era of increased access.

\section{Author contributions}

MCS is the guarantor. All authors contributed toward defining the study question, data analysis, drafting and revising the paper and agree to be accountable for all aspects of the work.

\section{Disclosure}

The authors report no conflicts of interest in this work.

\section{References}

1. Hajizadeh M. Legalizing and Regulating Marijuana in Canada: Review of Potential Economic, Social, and Health Impacts. Int J Health Policy Manag. 2016;5(8):453-456.

2. Andrew A. Monte AA, Zane RD, Heard KJ. The Implications of Marijuana Legalization in Colorado. JAMA. 2015;313(3):241-242.

3. Cerda M, Kilmer B. Uruguay's middle-ground approach to cannabis legalization. Int J Drug Policy. 2017;42:118-120.

4. Cox C. The Canadian Cannabis Act legalizes and regulates recreational cannabis use in 2018. Health Policy. 2018;122(3):205-209. 
5. Tibbo P, Crocker CE, Lam RW, Meyer J, Sareen J, Aitchison KJ. Implications of Cannabis Legalization on Youth and Young Adults. Can J Psychiatry. 2018;63(1):65-71.

6. Cerdá M, Wall M, Feng T, et al. Association of state recreational marijuana laws with adolescent marijuana use. JAMA Pediatr. 2017;171(2):142-149.

7. Miech RA, Johnston LD, O'Malley PM, Bachman JG, Schulenberg JE. Monitoring the Future National Survey Results on Drug use. 1975-2015: Volume I, Secondary School Students. Ann Arbor: Institute for Social Research, The University of Michigan; 2016.

8. Johnston LD, O'Malley PM, Bachman JG, Schulenberg JE. Monitoring the Future: National Survey Results on Drug Use, 19752009. Volume I: Secondary School Students. (NIH Publication No. 10-7584). Bethesda, MD: National Institute on Drug Abuse; 2010.

9. Wang GS, Le Lait MC, Deakyne SJ, Bronstein AC, Bajaj L, Roosevelt G. Unintentional Pediatric Exposures to Marijuana in Colorado, 20092015. JAMA Pediatr. 2016;170(9):e160971.

10. Grant CN, Bélanger RE, Cannabis BRE. Cannabis and Canada's children and youth. Paediatr Child Health. 2017;22(2):98-102.

11. Lisdahl KM, Wright NE, Kirchner-Medina C, Maple KE, Shollenbarger S. Considering Cannabis: The Effects of Regular Cannabis Use on Neurocognition in Adolescents and Young Adults. Curr Addict Rep. 2014;1(2):144-156.

12. Jager G, Block RI, Luijten M, Ramsey NF. Cannabis use and memory brain function in adolescent boys: a cross-sectional multicenter functional magnetic resonance imaging study. J Am Acad Child Adolesc Psychiatry. 2010;49(6):561-572.

13. Rey JM, Sawyer MG, Raphael B, Patton GC, Lynskey M. Mental health of teenagers who use cannabis. Results of an Australian survey. $\mathrm{Br} J$ Psychiatry. 2002;180(3):216-221.

14. Lei MK, Beach SRH, Simons RL. Childhood trauma, pubertal timing, and cardiovascular risk in adulthood. Health Psychology. 2018;37(7):613-617.

15. Finkelstein JS, Klibanski A, Neer RM. A longitudinal evaluation of bone mineral density in adult men with histories of delayed puberty. J Clin Endocrinol Metab. 1996;81(3):1152-1155.

16. Zhu J, Chan YM. Adult Consequences of Self-Limited Delayed Puberty. Pediatrics. 2017;139(6):e20163177.

17. Rogol AD. Growth at puberty: interaction of androgens and growth hormone. Med Sci Sports Exerc. 1994;26(6):767-770.

18. Wheeler MD. Physical changes of puberty. Endocrinol Metab Clin North Am. 1991;20(1):1-14.

19. Day FR, Elks CE, Murray A, Ong KK, Perry JR. Puberty timing associated with diabetes, cardiovascular disease and also diverse health outcomes in men and women: the UK Biobank study. Sci Rep. 2015;5:11208.

20. Prentice P, Viner RM. Pubertal timing and adult obesity and cardiometabolic risk in women and men: a systematic review and meta-analysis. Int J Obes. 2013;37(8):1036-1043.

21. Ahmed ML, Ong KK, Dunger DB. Childhood obesity and the timing of puberty. Trends Endocrinol Metab. 2009;20(5):237-242.

22. Golub MS, Collman GW, Foster PM, et al. Public health implications of altered puberty timing. Pediatrics. 2008;121(Supplement 3): S218-S230.

23. Finkelstein JS, Neer RM, Biller BM, Crawford JD, Klibanski A. Osteopenia in men with a history of delayed puberty. $N$ Engl J Med. 1992;326(9):600-604.

24. Frontini MG, Srinivasan SR, Berenson GS. Longitudinal changes in risk variables underlying metabolic Syndrome $\mathrm{X}$ from childhood to young adulthood in female subjects with a history of early menarche: the Bogalusa Heart Study. Int J Obes Relat Metab Disord. 2003;27(11):1398-1404.

25. Wenger T, Croix D, Tramu G. The Effect of Chronic Prepubertal Administration of Marihuana (Delta-9-Tetrahydrocannabinol) on the Onset of Puberty and the Postpubertal Reproductive Functions in Female Rats. Biology of Reproduction. 1988;39(3):540-545.
26. Field E, Tyrey L. Delayed sexual maturation in the female rat during chronic exposure to delta-9-tetrahydrocannabinol. Life Sci. 1984;35(17):1725-1730.

27. Field E, Tyrey L. Delayed sexual maturation during prepubertal cannabinoid treatment: importance of the timing of treatment. Journal of Pharmacology and Experimental Therapeutics. 1990;254(1):171-175.

28. Gupta D, Elbracht C. Effect of tetrahydrocannabinols on pubertal body weight spurt and sex hormones in developing male rats. Res Exp Med. 1983;182(2):95-104.

29. Copeland KC, Underwood LE, van Wyk JJ. Marihuana smoking and pubertal arrest. J Pediatr. 1980;96(6):1079-1080.

30. Kolodny RC, Masters WH, Kolodner RM, Toro G. Depression of plasma testosterone levels after chronic intensive marihuana use. N Engl J Med. 1974;290(16):872-874.

31. Marshall WA, Tanner JM. Variations in pattern of pubertal changes in girls. Arch Dis Child. 1969;44(235):291-303.

32. Marshall WA, Tanner JM. Variations in the pattern of pubertal changes in boys. Arch Dis Child. 1970;45(239):13-23.

33. Higgins JPT, Altman DG, Sterne JAC. Assessing risk of bias in included studies. In. Higgins JPT, Green S, editors. Cochrane Handbook for Systematic Reviews of Interventions Version 5.1.0. The Cochrane Collaboration; 2011.

34. Stang A. Critical evaluation of the Newcastle-Ottawa scale for the assessment of the quality of nonrandomized studies in meta-analyses. Eur J Epidemiol. 2010;25(9):603-605.

35. Atkins D, Best D, Briss PA, et al; GRADE Working Group. Grading quality of evidence and strength of recommendations. BMJ. 2004;328(7454):1490-1490.

36. Deeks J, Higgins JPT, Altman DG, Higgins J, Green S. Chapter 9: Analysing data and undertaking meta-analyses. In: Higgins JPT, Green S, editors. Cochrane Handbook for Systematic Reviews of Interventions 5.0.0. [Updated July. 2011]. The Cochrane Collaboration, 2011.

37. Sterne JAC, Egger M, Moher D. editors. Chapter 10: Addressing reporting biases. In: Higgins JPT, Green S, editors. Cochrane Handbook for Systematic Reviews of Intervention Version 5.1.0 [Updated March 2011]. The Cochrane Collaboration, 2011.

38. Jabeen S, Raja GK, Akram M, Ahmad A, Qayyum M, Rizvi SR. Evidence of stimulation of pubertal development and suppression of growth rate in boys smoking marijuana in cigarettes. Endocrine Abstracts; 2015.

39. Atakan Z, Cannabis AZ. Cannabis, a complex plant: different compounds and different effects on individuals. Ther Adv Psychopharmacol. 2012;2(6):241-254.

40. Kuhn C, Ignar D, Windh R. Endocrine function as a target of perinatal drug effects: methodologic issues. NIDA Res Monogr. 1991;114:206-232.

41. Wenger T, Croix D, Tramu G, Leonardelli J. Marijuana and reproduction. Effects on puberty and gestation in female rats. Experimental results. Ann Endocrinol. 1992;53(1):37-43.

42. Smith CG, Besch NF, Smith RG, Besch PK. Effect of Tetrahydrocannabinol on the Hypothalamic-Pituitary Axis in the Ovariectomized Rhesus Monkey. Fertility \& Sterility. 1979;31(3):335-339.

43. Howles CM. Role of LH and FSH in ovarian function. Mol Cell Endocrinol. 2000;161(1-2):25-30.

44. Bordini B, Rosenfield RL. Normal pubertal development. Pediatr Rev. 2011;32(6):223.

45. Government of Canada. Access to Cannabis for Medical Purposes Regulations - Daily Amount Fact Sheet (Dosage). Cannabis in Canada: Government of Canada; 2016.

46. Anai T, Miyazaki F, Tomiyasu T, Matsuo T. Risk of irregular menstrual cycles and low peak bone mass during early adulthood associated with age at menarche. Pediatr Int. 2001;43(5):483-488.

47. Komura H, Miyake A, Chen CF, Tanizawa O, Yoshikawa H. Relationship of age at menarche and subsequent fertility. Eur J Obstet Gynecol Reprod Biol. 1992;44(3):201-203.

48. Mueller BA, Daling JR, Weiss NS, Moore DE. Recreational drug use and the risk of primary infertility. Epidemiology. 1990;1(3):195-200.

49. Buck GM, Sever LE, Batt RE, Mendola P. Life-style factors and female infertility. Epidemiology. 1997;8(4):435-441. 
50. Lotfi N, Khazaei M, Shariatzadeh SMA, Soleimani Mehranjani M, Ghanbari A. The effect of cannabis sativa hydroalcoholic extract on sperm parameters and testis histology in rats. Int J Morphol. 2013;31(1):82-86.
51. Gundersen TD, Jørgensen N, Andersson AM, et al. Association between use of marijuana and male reproductive hormones and semen quality: a study among 1,215 healthy young men. Am J Epidemiol. 2015;1826:473-481 


\section{Supplementary materials}

Table SI Preferred reporting items for systematic review and meta-analysis checklist

\begin{tabular}{|c|c|c|c|}
\hline Section/topic & \# & Checklist item & $\begin{array}{l}\text { Reported on } \\
\text { page \# }\end{array}$ \\
\hline \multicolumn{4}{|l|}{ Title } \\
\hline Title & $\mathrm{I}$ & Identify the report as a systematic review, meta-analysis, or both. & I \\
\hline \multicolumn{4}{|l|}{ Abstract } \\
\hline Structured summary & 2 & $\begin{array}{l}\text { Provide a structured summary including, as applicable: background; objectives; data sources; study } \\
\text { eligibility criteria, participants, and interventions; study appraisal and synthesis methods; results; } \\
\text { limitations; conclusions and implications of key findings; systematic review registration number. }\end{array}$ & 3 \\
\hline \multicolumn{4}{|l|}{ Introduction } \\
\hline Rationale & 3 & Describe the rationale for the review in the context of what is already known. & $4-5$ \\
\hline Objectives & 4 & Provide an explicit statement of questions being addressed with reference to PICOS. & 5 \\
\hline \multicolumn{4}{|l|}{ Methods } \\
\hline $\begin{array}{l}\text { Protocol and } \\
\text { registration }\end{array}$ & 5 & $\begin{array}{l}\text { Indicate if a review protocol exists, if and where it can be accessed (eg, Web address), and, if } \\
\text { available, provide registration information including registration number. }\end{array}$ & $\begin{array}{l}5 \text { (registration } \\
\text { number) }\end{array}$ \\
\hline Eligibility criteria & 6 & $\begin{array}{l}\text { Specify study characteristics (eg, PICOS and length of follow-up) and report characteristics (e.g., } \\
\text { years considered, language, and publication status) used as criteria for eligibility, giving rationale. }\end{array}$ & $5-6$ \\
\hline Information sources & 7 & $\begin{array}{l}\text { Describe all information sources (e.g., databases with dates of coverage and contact with study } \\
\text { authors to identify additional studies) in the search and date last searched. }\end{array}$ & $5-6$ \\
\hline Search & 8 & $\begin{array}{l}\text { Present full electronic search strategy for at least one database, including any limits used, such that } \\
\text { it could be repeated. }\end{array}$ & I8 (Table I) \\
\hline Study selection & 9 & $\begin{array}{l}\text { State the process for selecting studies (ie, screening, eligibility, included in systematic review, and, if } \\
\text { applicable, included in the meta-analysis). }\end{array}$ & 6 \\
\hline $\begin{array}{l}\text { Data collection } \\
\text { process }\end{array}$ & 10 & $\begin{array}{l}\text { Describe the method of data extraction from reports (eg, piloted forms, independently, and in } \\
\text { duplicate) and any processes for obtaining and confirming data from investigators. }\end{array}$ & 6 \\
\hline Data items & 11 & $\begin{array}{l}\text { List and define all variables for which data were sought (eg, PICOS and funding sources) and any } \\
\text { assumptions and simplifications made. }\end{array}$ & 6 \\
\hline $\begin{array}{l}\text { Risk of bias in } \\
\text { individual studies }\end{array}$ & 12 & $\begin{array}{l}\text { Describe methods used for assessing risk of bias of individual studies (including specification of } \\
\text { whether this was done at the study or outcome level), and how this information is to be used in } \\
\text { any data synthesis. }\end{array}$ & $6-7$ \\
\hline Summary measures & 13 & State the principal summary measures (eg, risk ratio and difference in means). & 7 \\
\hline Synthesis of results & 14 & $\begin{array}{l}\text { Describe the methods of handling data and combining results of studies, if done, including measures } \\
\text { of consistency }\left(e g, I^{2}\right) \text { for each meta-analysis. }\end{array}$ & 7 \\
\hline Section/topic & \# & Checklist item & $\begin{array}{l}\text { Reported on } \\
\text { page \# }\end{array}$ \\
\hline $\begin{array}{l}\text { Risk of bias across } \\
\text { studies }\end{array}$ & 15 & $\begin{array}{l}\text { Specify any assessment of risk of bias that may affect the cumulative evidence (eg, publication bias } \\
\text { and selective reporting within studies). }\end{array}$ & 7 \\
\hline Additional analyses & 16 & $\begin{array}{l}\text { Describe methods of additional analyses (eg, sensitivity or subgroup analyses and meta-regression), } \\
\text { if done, indicating which were pre-specified. }\end{array}$ & 7 \\
\hline \multicolumn{4}{|l|}{ Results } \\
\hline Study selection & 17 & $\begin{array}{l}\text { Give numbers of studies screened, assessed for eligibility, and included in the review, with reasons } \\
\text { for exclusions at each stage, ideally with a flow diagram. }\end{array}$ & $\begin{array}{l}7,18 \\
\text { (Figure I) }\end{array}$ \\
\hline Study characteristics & 18 & $\begin{array}{l}\text { For each study, present characteristics for which data were extracted (eg, study size, PICOS, and } \\
\text { follow-up period) and provide the citations. }\end{array}$ & $7-8$ \\
\hline $\begin{array}{l}\text { Risk of bias within } \\
\text { studies }\end{array}$ & 19 & $\begin{array}{l}\text { Present data on risk of bias of each study and, if available, any outcome level assessment (see item } \\
\text { 12). }\end{array}$ & $\mathrm{N} / \mathrm{A}$ \\
\hline $\begin{array}{l}\text { Results of individual } \\
\text { studies }\end{array}$ & 20 & $\begin{array}{l}\text { For all outcomes considered (benefits or harms), present, for each study: (a) simple summary data } \\
\text { for each intervention group and (b) effect estimates and Cls, ideally with a forest plot. }\end{array}$ & $7-8$ \\
\hline Synthesis of results & 21 & Present results of each meta-analysis done, including Cls and measures of consistency. & $\mathrm{N} / \mathrm{A}$ \\
\hline $\begin{array}{l}\text { Risk of bias across } \\
\text { studies }\end{array}$ & 22 & Present results of any assessment of risk of bias across studies (see Item I5). & N/A \\
\hline Additional analysis & 23 & $\begin{array}{l}\text { Give results of additional analyses, if done (eg, sensitivity or subgroup analyses and meta-regression } \\
\text { [see Item I6]). }\end{array}$ & N/A \\
\hline
\end{tabular}

(Continued) 
Table SI (Continued)

\begin{tabular}{|c|c|c|c|}
\hline Section/topic & $\#$ & Checklist item & $\begin{array}{l}\text { Reported on } \\
\text { page \# }\end{array}$ \\
\hline \multicolumn{4}{|l|}{ Discussion } \\
\hline $\begin{array}{l}\text { Summary of } \\
\text { evidence }\end{array}$ & 24 & $\begin{array}{l}\text { Summarize the main findings including the strength of evidence for each main outcome; consider } \\
\text { their relevance to key groups (eg, health care providers, users, and policy makers). }\end{array}$ & 8 \\
\hline Limitations & 25 & $\begin{array}{l}\text { Discuss limitations at study and outcome level (eg, risk of bias) and at review-level (eg, incomplete } \\
\text { retrieval of identified research and reporting bias). }\end{array}$ & 10 \\
\hline Conclusions & 26 & $\begin{array}{l}\text { Provide a general interpretation of the results in the context of other evidence and implications for } \\
\text { future research. }\end{array}$ & $10-11$ \\
\hline \multicolumn{4}{|l|}{ Funding } \\
\hline Funding & 27 & $\begin{array}{l}\text { Describe sources of funding for the systematic review and other support (eg, supply of data); role } \\
\text { of funders for the systematic review. }\end{array}$ & 12 \\
\hline
\end{tabular}

Note: Adapted from Moher D, Liberati A, Tetzlaff J, Altman DG, The PRISMA Group (2009). Preferred Reporting Items for Systematic Reviews and Meta-Analyses: The PRISMA Statement. PLoS Med 6(7):el000097.'

Abbreviation: PICOS, participants, interventions, comparisons, outcomes, and study design.

Table S2 Cochrane central register of controlled trials search strategy

\begin{tabular}{|l|l|}
\hline$\#$ & Searches \\
\hline I & Cannabis/ \\
\hline 2 & exp Cannabinoids/ \\
\hline 3 & marijuana.mp. \\
\hline 4 & cannabi*.mp. \\
\hline 5 & marihuana.mp. \\
\hline 6 & ganja*.mp. \\
\hline 7 & bhang*.mp. \\
\hline 8 & or/I-7 \\
\hline 9 & exp Puberty/ \\
\hline 10 & pubert*.mp. \\
\hline 11 & sex* precoci*.mp. \\
\hline 12 & puberty, delayed/or puberty, precocious/ \\
\hline 13 & Sexual Development/ \\
\hline 14 & Sexual Maturation/ \\
\hline 15 & (sexual adj2 (development or matur*)).mp. \\
\hline 16 & or/9-I5 \\
\hline 17 & 8 and I6 \\
\hline 18 & remove duplicates from I7 \\
\hline 19 & I8 not (animals/not (humans/and animals/)) \\
\hline
\end{tabular}

Table S3 Cochrane database of systematic reviews search strategy

\begin{tabular}{|l|l|}
\hline$\#$ & Searches \\
\hline 1 & {$[$ Cannabis/] } \\
\hline 2 & {$[$ exp Cannabinoids/] } \\
\hline 3 & marijuana.mp. \\
\hline 4 & cannabi*.mp. \\
\hline 5 & marihuana.mp. \\
\hline 6 & ganja*.mp. \\
\hline 7 & bhang*.mp. \\
\hline 8 & or/I-7 \\
\hline 9 & {$[$ exp Puberty/] } \\
\hline 10 & pubert*.mp. \\
\hline 11 & sex* precoci*.mp. \\
\hline 12 & {$[$ puberty, delayed/or puberty, precocious/] } \\
\hline 13 & {$[$ Sexual Development/] } \\
\hline 14 & {$[$ Sexual Maturation/] } \\
\hline 15 & (sexual adj2 (development or matur*)).mp. \\
\hline 16 & or/9-I5 \\
\hline 17 & 8 and I6 \\
\hline 18 & remove duplicates from I7 \\
\hline 19 & II8 not (animals/not (humans/and animals/)) \\
\hline
\end{tabular}


Table S4 PsycINFO search strategy

\begin{tabular}{|l|l|}
\hline$\#$ & Searches \\
\hline 1 & Cannabis/ \\
\hline 2 & exp Cannabinoids/ \\
\hline 3 & marijuana.mp. \\
\hline 4 & cannabi*.mp. \\
\hline 5 & marihuana.mp. \\
\hline 6 & ganja*.mp. \\
\hline 7 & bhang*.mp. \\
\hline 8 & or/I-7 \\
\hline 9 & Puberty/ \\
\hline 10 & pubert*.mp. \\
\hline 11 & sex* precoci*.mp. \\
\hline 12 & menarche/ \\
\hline 13 & menarche.mp. \\
\hline 14 & adrenarche.mp. \\
\hline 15 & Sexual Development/ \\
\hline 16 & (sexual adj2 (development or matur*)).mp. \\
\hline 17 & or/9-I6 \\
\hline 18 & 8 and I7 \\
\hline 19 & remove duplicates from I8 \\
\hline 20 & 19 not (animals/not (humans/and animals/)) \\
\hline
\end{tabular}

Table S5 Embase search strategy

\begin{tabular}{|c|c|}
\hline \# & Searches \\
\hline $\mathrm{I}$ & cannabis/ \\
\hline 2 & $\begin{array}{l}\text { cannabinoid/or cannabichromene/or cannabidiol/or } \\
\text { cannabinol/or dronabinol/ }\end{array}$ \\
\hline 3 & cannabi*.mp. \\
\hline 4 & marihuana.mp. \\
\hline 5 & marijuana.mp. \\
\hline 6 & ganja*.mp. \\
\hline 7 & bhang*.mp. \\
\hline 8 & dronabinol*.mp. \\
\hline 9 & or/l-8 \\
\hline 10 & exp puberty/ \\
\hline $\mathrm{II}$ & pubert*.mp. \\
\hline 12 & menarche.mp. \\
\hline 13 & adrenarche.mp. \\
\hline 14 & delayed puberty/ \\
\hline 15 & precocious pubertyl \\
\hline 16 & sex* precoci*.mp. \\
\hline 17 & pubarche.mp. \\
\hline 18 & thelarche.mp. \\
\hline 19 & sexual development/ \\
\hline 20 & sexual maturation/ \\
\hline 21 & (sexual adj2 (development or matur*)).mp. \\
\hline 22 & or/I0-2I \\
\hline 23 & 9 and 22 \\
\hline 24 & remove duplicates from 23 \\
\hline 25 & 24 not (animals/not (humans/and animals/)) \\
\hline
\end{tabular}

Table S6 Web of science search strategy

(marijuana or cannabi* or marihuana or ganja* or bhang*) AND TOPIC: (pubert* or menarche or adrenarche or sexual development or sexual matur* or sex* preocoicious*) Indexes = SCI-EXPANDED, SSCI, A\&HCl, CPCI-S, CPCI-SSH, ESCI Timespan = All years
Table S7 SPORTDiscus search strategy

\begin{tabular}{|l|l|}
\hline$\#$ & Searches \\
\hline SI & cannabi* \\
\hline S2 & DE "CANNABIS" \\
\hline S3 & marijuana or marihuana or ghanja or bhang \\
\hline S4 & SI OR S2 OR S3 \\
\hline S5 & pubert* \\
\hline S6 & DE "PUBERTY" OR DE "MENARCHE" \\
\hline S7 & menarche or adrenarche Search modes - \\
\hline S8 & sexual maturation \\
\hline S9 & sex* precoci* \\
\hline SI0 & sexual N2 (development or matur*) \\
\hline SII & S5 OR S6 OR S7 OR S8 OR S9 OR SI0 \\
\hline S12 & S4 AND SII \\
\hline
\end{tabular}

Table S8 CINAHL search strategy

\begin{tabular}{|l|l|}
\hline$\#$ & Searches \\
\hline S1 & (MH "Cannabis") \\
\hline S2 & $\begin{array}{l}\text { "marijuana" or "cannabi*” or "marihuana" or "ganja*” or } \\
\text { "bhang*" }\end{array}$ \\
\hline S3 & SI OR S2 \\
\hline S4 & (MH "Puberty+") \\
\hline S5 & "pubert*” or “menarche" or "adrenarche" \\
\hline S6 & $\begin{array}{l}\text { (MH "Puberty, Precocious") OR (MH "Puberty, } \\
\text { Delayed") }\end{array}$ \\
\hline S7 & "sex* precocious*” \\
\hline S8 & sexual N2 (development or matur*) \\
\hline S9 & S4 OR S5 OR S6 OR S7 OR S8 \\
\hline S10 & S3 AND S9 \\
\hline
\end{tabular}

Table S9 ProQuest dissertations and theses A\&l search strategy Searches

All ((marijuana OR cannabi* OR marihuana OR ganja* OR bhang*)) AND all ((pubert* or menarche or adrenarche or sexual development or sexual matur* or sex* preocoicious*))

\section{Reference}

1. Moher D, Liberati A, Tetzlaff J, Altman DG, The PRISMA Group. Preferred Reporting Items for Systematic Reviews and Meta-Analyses: The PRISMA Statement. PLoS Med. 2009;6(7):e1000097. 


\section{Publish your work in this journal}

Adolescent Health, Medicine and Therapeutics is an international, peer-reviewed, open access journal focusing on health, pathology, and treatment issues specific to the adolescent age group. All aspects of health maintenance, preventative measures and disease treatment interventions are addressed within the journal and practitioners from all disciplines are invited to submit their work as well as healthcare researchers and patient support groups. This journal is included in PubMed. The manuscript management system is completely online and includes a very quick and fair peer-review system. Visit http://www.dovepress.com/testimonials. php to read real quotes from published authors.

Submit your manuscript here: http://www.dovepress.com/adolescent-health-medicine-and-therapeutics-journal 